\title{
Influence of selected plant protection products on reducing the presence of fungi isolated from Chinese aster
}

\author{
Wpływ wybranych preparatów na ograniczanie \\ obecności grzybów izolowanych z astra chińskiego
}

\author{
Jacek Nawrocki
}

\section{Summary}

Field experiments were carried out in 2010 and 2011 on three dwarf cultivars of China-aster: Duszek, Skrzat and Srebrzysta Gwiazdka. The following biological plant protection products Polyversum WP (Pythium oligandrum), Trifender WP (Trichoderma asperellum) and preparations containing natural ingredients HF-Mycol (fennel oil - 23.08\%) and Prev-B2 (D-limonene - 4.2\%, boron 2.1\%) were applied. Fungicide Amistar $250 \mathrm{SC}$ (azoxystrobin $250 \mathrm{~g} / \mathrm{l}$ ) was used as a standard and unprotected plants were untreated control. Amistar 250 SC and Polyversum WP were the most efficient plant protection products limiting infection of plants by Fusarium oxysporum. Amistar 250 SC and Prev-B2 ihibited development of Botrytis cinerea, the cause of necrosis of inflorescences and aster shoots. Preventive treatments with Amistar 250 SC, Prev-B2 and Polyversum WP effectively limited occurrence of Alternaria spp. Fusarium spp. and Cladosporium spp. especially on aster leaves.

Key words: preparations containing natural ingredients, biological means, Chinese aster, fungal pathogens, communities of fungi

\section{Streszczenie}

Doświadczenia polowe przeprowadzono w latach 2010 i 2011 na 3 odmianach karłowych astra chińskiego: Duszek, Skrzat i Srebrzysta Gwiazdka. W badaniach zastosowano preparaty biologiczne: Polyversum WP (Pythium oligandrum) i Trifender WP (Trichoderma asperellum) oraz preparaty zawierające naturalne substancje: HF-Mycol (olejek fenkułowy - 23,08\%) i Prev-B2 (d-limonen - 4,2\%, bor - 2,1\%). Jako standardowy fungicyd użyto Amistar $250 \mathrm{SC}$ (azoksystrobina $250 \mathrm{~g} / \mathrm{I}$ ). Kontrolę stanowiły rośliny niechronione. Amistar 250 SC oraz Polyversum WP okazały się najskuteczniejszymi preparatami ograniczającymi porażenie roślin przez Fusarium oxysporum. Preparaty Amistar 250 SC oraz Prev-B2 hamowały rozwój Botrytis cinerea, sprawcy zgorzeli kwiatostanów i pędów. Profilaktyczne opryskiwanie środkami Amistar 250 SC, Prev-B2 i Polyversum WP skutecznie limitowało występowanie Alternaria spp., Fusarium spp. i Cladosporium spp., szczególnie na liściach astra.

Słowa kluczowe: preparaty zawierające substancje naturalne, środki biologiczne, aster chiński, patogeny grzybowe, zbiorowiska grzybów

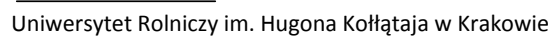

Katedra Ochrony Roślin

Al. 29 Listopada 54, 31-425 Kraków

j.nawrocki@ogr.ur.krakow.pl 


\section{Wstęp / Introduction}

Do najczęściej występujących mikoz astra chińskiego, powodujących zamieranie roślin w trakcie uprawy, należy fuzarioza naczyniowa powodowana przez Fusarium oxysporum f. sp. callistephi oraz rizoktonioza, której sprawcą jest Thanatephorus cucumeris. Objawy chorobowe na liściach może wywoływać Golovinomyces cichoracearum sprawca mączniaka prawdziwego oraz patogeny powodujące plamistości liści: Ascochyta sp., Phyllosticta sp. czy Septoria sp. Duże szkody może powodować wystąpienie na kwiatostanach astra szarej pleśni, której sprawcą jest Botryotinia fuckeliana (Orlikowski i Saniewska 1988; Saniewska 1991; Horst 2008). W celu ograniczenia strat powodowanych przez patogeny atakujące liście, pędy i kwiatostany astra chińskiego zaleca się stosowanie opryskiwań standardowymi fungicydami. Obecnie dużą rolę przypisuje się preparatom biologicznym i zawierającym substancje naturalne, które można wykorzystywać w ochronie roślin w uprawach ekologicznych i terenach chronionych (Saniewska 1993, 2001).

Celem pracy było określenie wpływu wybranych preparatów biologicznych i zawierających substancje naturalne zastosowanych profilaktycznie $\mathrm{w}$ okresie wegetacji astra chińskiego na zbiorowiska grzybów izolowanych z chorych roślin.

\section{Materiały i metody / Materials and methods}

Doświadczenia polowe przeprowadzono w latach 2010 i 2011 na trzech odmianach karłowych astra chińskiego:
Duszek, Skrzat i Srebrzysta Gwiazdka. W badaniach zastosowano preparaty biologiczne: Polyversum WP $\left(10^{6}\right.$ oospor Pythium oligandrum w 1 g) i Trifender WP $\left(5 \times 10^{8}\right.$ zarodników Trichoderma asperellum w $\left.1 \mathrm{~g}\right)$ oraz preparaty zawierające substancje naturalne: HF-Mycol (olejek fenkułowy - 23,08\%) i Prev-B2 (d-limonen $4,2 \%$, bor - 2,1\%). Jako standardowy fungicyd użyto Amistar 250 SC (azoksystrobina 250 g/l). Rośliny opryskiwano 4-krotnie w ciagu okresu wegetacji. Trifender WP wprowadzano do gleby podlewając rośliny. Kontrolę stanowiły rośliny niechronione. Każdą kombinację stanowiło 25 roślin w trzech powtórzeniach. W trakcie wegetacji z nadziemnych części roślin izolowano grzyby na podłoża agarowo-glukozowo-ziemniaczne PDA (Potato Dextrose Agar) i maltozowe MA (malt agar), przeprowadzając uprzednio odkażanie powierzchniowe chorych tkanek w roztworze $70 \%$ alkoholu etylowego lub nad płomieniem palnika. Identyfikację wyizolowanych grzybów dokonano na podstawie kluczy mikologicznych (Nawrocki 2008).

\section{Wyniki i dyskusja / Results and discussion}

Podczas wegetacji na astrach najczęściej obserwowanymi zmianami chorobowymi były: pasożytnicze więdnięcie całych roślin, plamistości liści, zgorzele pędów oraz zamieranie całych kwiatostanów. Najczęściej izolowanymi grzybami z więdnących roślin, niezależnie od odmiany były grzyby rodzaju Fusarium oraz Rhizoctonia solani. Dominującymi izolatami z porażonych liści i pędów astra były: Botrytis cinerea, Alternaria alternata,

Tabela 1. Występowanie grzybów w chorych roślinach astra odmiany Duszek (średnio dla lat 2010 i 2011)

Table 1. Fungi occurrence in infected asters cultivar Duszek (average for years 2010 and 2011)

\begin{tabular}{|c|c|c|c|c|c|c|}
\hline \multirow{2}{*}{$\begin{array}{l}\text { Gatunek grzyba } \\
\text { Fungus species }\end{array}$} & \multicolumn{6}{|c|}{$\begin{array}{l}\text { Średnie liczby izolatów w kombinacjach } \\
\text { Average number of isolates in combinations }\end{array}$} \\
\hline & $\mathrm{I}$ & II & III & IV & $\mathrm{V}$ & VI \\
\hline Alternaria alternata & 5,5 & 10,5 & 11,5 & 6 & 3,5 & 13,5 \\
\hline Aspergillus niger & & 1 & & & & 1,5 \\
\hline Botrytis cinerea & 6 & 7,5 & 9,5 & 3 & 1,5 & 8 \\
\hline Cladosporium cladosporioides & 1,5 & 4,5 & 5 & 2 & & 5,5 \\
\hline Cylindrocarpon destructans & 1,5 & & 1 & 2 & & 2,5 \\
\hline C. didymum & 1 & 1,5 & 2 & 1 & 1,5 & 2 \\
\hline Epicoccum nigrum & 1 & & & 1 & 2 & 3 \\
\hline Fusarium avenaceum & 1 & 1 & 2 & & 1 & 3,5 \\
\hline F. culmorum & 0,5 & 2 & 1,5 & 0,5 & & 2,5 \\
\hline F. oxysporum & 5,5 & 9 & 13,5 & 10,5 & 4,5 & 14,5 \\
\hline F. solani & & 1 & 1,5 & & & 2 \\
\hline Penicillium spp. & 2 & 1 & 3,5 & 3 & 1,5 & 2 \\
\hline Rhizoctonia solani & 2 & 1,5 & 3 & 2,5 & 1,5 & 3,5 \\
\hline Sclerotinia sclerotiorum & & & 0,5 & & & 1,5 \\
\hline Sordaria macrospora & & & 1 & 1,5 & & 1,5 \\
\hline Trichoderma harzianum & 1,5 & & & & & 0,5 \\
\hline T. viride & & & & 1 & & 1 \\
\hline
\end{tabular}

I - Polyversum WP; II - Trifender WP; III - HF-Mycol; IV - Prew-B2; V - Amistar 250 SC; VI - kontrola - control 
Tabela 2. Występowanie grzybów w chorych roślinach astra odmiany Skrzat (średnio dla lat 2010 i 2011)

Table 2. Fungi occurrence in infected asters cultivar Skrzat (average for years 2010 and 2011)

\begin{tabular}{|c|c|c|c|c|c|c|}
\hline \multirow{2}{*}{$\begin{array}{l}\text { Gatunek grzyba } \\
\text { Fungus species }\end{array}$} & \multicolumn{6}{|c|}{$\begin{array}{l}\text { Średnie liczby izolatów w kombinacjach } \\
\text { Average number of isolates in combinations }\end{array}$} \\
\hline & $\mathrm{I}$ & II & III & IV & $\mathrm{V}$ & VI \\
\hline Alternaria alternata & 7,5 & 11 & 14,5 & 8 & 5,5 & 16 \\
\hline Botrytis cinerea & 4 & 4,5 & 6,5 & 2,5 & 1 & 6,5 \\
\hline Cladosporium cladosporioides & 1 & 3 & 3 & 1 & 0,5 & 2,5 \\
\hline Cylindrocarpon didymum & 3,5 & 2 & 2,5 & 1,5 & 1 & 3 \\
\hline Epicoccum nigrum & 2,5 & 2,5 & 2 & 1,5 & 2,5 & 4,5 \\
\hline Fusarium avenaceum & & 1,5 & 3 & & 1 & 3,5 \\
\hline F. culmorum & 0,5 & & 1 & 1,5 & & 1,5 \\
\hline F. oxysporum & 4,5 & 7 & 10,5 & 8,5 & 2,5 & 11,5 \\
\hline F. solani & 0,5 & & 0,5 & & & \\
\hline Penicillium spp. & 3 & 2,5 & 2,5 & 4 & 35 & 4 \\
\hline Rhizoctonia solani & 1 & 0,5 & 2 & 1,5 & 2 & 2,5 \\
\hline Sclerotinia sclerotiorum & & & 0,5 & & & 0,5 \\
\hline Trichoderma harzianum & 1 & 0,5 & & & 1 & \\
\hline T. viride & & & 0,5 & 1 & 1 & 1,5 \\
\hline
\end{tabular}

I - Polyversum WP; II - Trifender WP; III - HF-Mycol; IV - Prew-B2; V - Amistar 250 SC; VI - kontrola - control

Tabela 3. Występowanie grzybów w chorych roślinach astra odmiany Srebrzysta Gwiazdka (średnio dla lat 2010 i 2011)

Table 3. Fungi occurrence in infected asters cultivar Srebrzysta Gwiazdka (average for years 2010 and 2011)

\begin{tabular}{|c|c|c|c|c|c|c|}
\hline \multirow{2}{*}{$\begin{array}{l}\text { Gatunek grzyba } \\
\text { Fungus species }\end{array}$} & \multicolumn{6}{|c|}{$\begin{array}{l}\text { Średnie liczby izolatów w kombinacjach } \\
\text { Average number of isolates in combinations }\end{array}$} \\
\hline & $\mathrm{I}$ & II & III & IV & $\mathrm{V}$ & VI \\
\hline Alternaria alternata & 7,5 & 11,5 & 12,5 & 6,5 & 4,5 & 13,5 \\
\hline Botrytis cinerea & 5 & 7,5 & 6,5 & 3,5 & 2,5 & 6,5 \\
\hline Cladosporium cladosporioides & 1 & 2,5 & 3 & 2,5 & 0,5 & 3,5 \\
\hline Cylindrocarpon didymum & 0,5 & 1,5 & 2 & 2,5 & 1 & 1 \\
\hline Epicoccum nigrum & 3 & 2,5 & 3,5 & 1 & 1,5 & 3 \\
\hline Fusarium avenaceum & 0,5 & 1,5 & 2 & 1 & 0,5 & 3,5 \\
\hline F. culmorum & 1 & 2,5 & 2 & 1 & & 0,5 \\
\hline F. oxysporum & 6,5 & 8 & 12,5 & 12,5 & 5,5 & 15,5 \\
\hline Penicillium spp. & 3,5 & 2 & 3,5 & 2,5 & 1,5 & 2 \\
\hline Rhizoctonia solani & 1 & 1,5 & 3 & 1,5 & 1,5 & 3,5 \\
\hline Sclerotinia sclerotiorum & & 0,5 & & 0,5 & & 2,5 \\
\hline Trichoderma harzianum & & 0,5 & 1 & 0,5 & & 0,5 \\
\hline Trichoderma viride & & & & 0,5 & 1 & 2 \\
\hline
\end{tabular}

I - Polyversum WP; II - Trifender WP; III - HF-Mycol; IV - Prew-B2; V - Amistar 250 SC; VI - kontrola - control

Fusarium spp. i Cladosporium spp. Z porażonych kwiatostanów wielokrotnie wyosabniano Botrytis cinerea. Istotną rolę grzybów rodzaju Fusarium oraz $R$. solani jako sprawców więdnięcia i zamierania astrów potwierdzają wcześniejsze doniesienia (Saniewska 1991; Horst 2008).

Najmniej kolonii grzybów wyizolowano z roślin, wszystkich badanych odmian, które były opryskiwane standardowym fungicydem Amistar $250 \mathrm{SC}$ (tab. 1, 2, 3). Również preparat Polyversum WP wpływał na ograniczenie występowania grzybów izolowanych $\mathrm{z}$ chorych roślin wszystkich testowanych odmian. Z roślin chro- nionych środkami Polyversum WP i Amistar 250 SC nie izolowano groźnego polifaga Sclerotinia sclerotiorum. Najwięcej kultur grzybów wyosobniono z roślin odmiany Duszek, a najczęściej wyosabnianymi gatunkami grzybów $\mathrm{z}$ chorych astrów trzech badanych odmian okazały się A. alternata i F. oxysporum. Istotną rolę odmian w ograniczaniu porażenia astrów zwłaszcza przez Fusarium oxysporum wykazali Saniewska i wsp. (1992) oraz Necas i Kobza (2008). Zastosowanie preparatów Amistar 250 SC oraz Polyversum WP spowodowało ograniczenie występowania grzybów rodzaju Fusarium, zwłaszcza F. oxy- 
sporum, izolowanych z więdnących i zamierających roślin wszystkich testowanych odmian. Wcześniejsze badania Saniewskiej (2001) potwierdzają skuteczność Pythium oligandrum w ochronie astra przed fuzariozą. Liczbę wyosobnianych kultur grzybów: A. alteranta, Fusarium spp. oraz C. cladosporioides skutecznie ograniczały preparaty Amistar 250 SC, Prev-B2 i Polyversum WP. Ograniczenie rozwoju tych grzybów na zielonych częściach astra powodowało hamowanie wystapienia plamistości liści i pędów astra wszystkich badanych odmian. Najliczniej izolowano potencjalnie patogeniczne grzyby z obiektów kontrolnych. Preparaty Amistar 250 SC oraz Prev-B2 istotnie ograniczały występowanie $B$. cinerea, nie tylko w porażonych kwiatostanach, ale także w liściach i pędach astra. W badaniach in vitro Wilson i wsp. (1997) wykazali skuteczność d-limonenu (Prev-B2) w ograniczaniu wzrostu $B$. cinerea.

\section{Wnioski / Conclusions}

1. Amistar $250 \mathrm{SC}$ oraz Polyversum WP okazały się najskuteczniejszymi preparatami ograniczającymi porażenie roślin przez $F$. oxysporum.

2. Preparaty Amistar 250 SC oraz Prev-B2 ograniczały występowanie zgorzeli kwiatostanów astra powodowanej przez $B$. cinerea.

3. Profilaktyczne opryskiwanie środkami Amistar $250 \mathrm{SC}$, Prev-B2 i Polyversum WP wpływały na ograniczanie liczby izolatów A. alternata, Fusarium spp. i C. sporium cladosporioides wyosabnianych $\mathrm{z}$ liści astra.

\section{Literatura / References}

Horst R.K. 2008. Westcott's Plant Disease Handbook. Springer Verlag, Berlin, Heideberg, New York, 1317 pp.

Nawrocki J. 2008. Wpływ wybranych preparatów na występowanie grzybów zasiedlających bulwy mieczyka ogrodowego. Zesz. Probl. Post. Nauk Rol. 531: 145-150.

Necas T., Kobza F. 2008. Resistance of Chinese aster (Callistephus chinensis Nees.) to Fusarium wilts (Fusarium oxysporum f. sp. callistephi (Beach) Snyder and Hansen) evaluated using artificial inoculations. Hort. Sci. 35 (4): 151-161.

Orlikowski L.B., Saniewska A. 1988. Influence of some enviromental factors on the population density of Fusarium oxysporum f. sp. callistephi in soil. I. Occurrence of Fusarium oxysporum f. sp. callistephi and F. oxysporum on aster plants and in soil. Prace ISiK, Rośliny Ozdobne, B, 12: 177-180.

Saniewska A. 1991. Przyczyny więdnięcia i zamierania astrów chińskich (Callistephus chinensis (L.) Ness) w Polsce. Prace ISiK, Rośliny Ozdobne, B, 16: 171-180.

Saniewska A., Orlikowski L., Karpiński S., Rzepkowska A. 1992. Ocena odporności odmian astrów chińskich na Fusarium oxysporum f. sp. callistephi (Beach) Sny. et Hans. Prace ISiK, Rośliny Ozdobne, B, 17: 99-106.

Saniewska A. 1993. Możliwość biologicznej ochrony astrów przed fuzariozą naczyniową. Materiały 33. Sesji Nauk. Inst. Ochr. Roślin, cz. 2: $167-171$

Saniewska A. 2001. Możliwości wykorzystania biopreparatu Polyversum w ochronie astrów chińskich przed Fusarium oxysporum f. sp. callistephi. [Potential use of biopreparation Polyversum in the protection of China aster against Fusarium oxysporum f. sp. callistephi]. Prog. Plant Prot./Post. Ochr. Roślin 41 (2): 798-801.

Wilson C.L., Solar J.M., Ghaouth A.L., Wisniewski M.E. 1997. Rapid evaluation of plant extracts and essential oils for antifungal activity against Botrytis cinerea. Plant Dis. 81 (2): 204-210. 